\title{
The Application of Chinese Traditional Elements Design in Industrial Design
}

\author{
Nan Li \\ Qingdao binhai University \\ 691525115@qq.com
}

Keywords: Chinese elements; Industrial design; Traditional culture; Symbols

\begin{abstract}
This paper presents the application of Chinese traditional elements in modern industrial design. Taking some successful car design as an example, this paper studies the styling elements and styling styles, and explains how to introduce Chinese traditional elements into the modern industrial design process. Elements into symbolic symbols, and issues to be aware of when using these symbols in industrial design.
\end{abstract}

\section{Introduction}

China's rapid development has made great achievements in the world recognized, and this process more people into the high-income groups of modern batch transformation, which will lead to the rapid development of Chinese design, gave birth to a variety of Chinese elements and modern civilization The design, these designs will promote the Chinese design style to the world, the success of the design is always coincidental with the needs of the times. In such a variety of schools with a variety of ideas, with national character will flash, the nation is the world. Such a large environment, our industrial design will also continue to appear with the traditional elements of the new design, domestic and foreign design recognition and praise, embodies the essence of mining a strong civilization and modern design trends in the rub; Will issue a magnificent new design for the colorful. Which does not Pan with Chinese characteristics of modern industrial design The use of Chinese element design will be compelling, and the convergence of the splendid splendor of the national culture of light is a deep Chinese cultural heritage.

\section{Chinese Elements and Their Connotations}

When it comes to Chinese elements, we think of Chang'e-1, the Chinese torch, the Olympic mascot, the China Pavilion and the Kung Fu Panda. The design of China attracts the attention of various countries while spreading the splendid culture of China. Designers have to the next few years, the design direction of the Chinese elements of the development and design, through professional analysis found that the traditional elements of traditional Chinese culture connotation, a good performance of its unique style.

Chinese Elements and Their Connotations. Chinese elements --- all in the process of integration, evolution and development of the Chinese nation gradually formed by the Chinese people to create, inheritance, reflecting the Chinese humanistic spirit and folk psychology, with Chinese characteristics of cultural achievements, are Chinese elements, including tangible Material symbols and intangible spiritual content, that is, material and cultural elements of spiritual and cultural elements. Such as ideology, moral values, value systems, folk customs, living habits, religious beliefs, architecture, art, technology, law, ethics. Chinese traditional culture is Chinese elements, but Chinese elements are not equal to Chinese traditional culture, but also include Chinese modern culture. Modern designers should be impetuous, simple design thinking into a calm and rational with a cultural temperament, not only in the design of the surface of the product, pay more attention to the performance of deep-seated cultural connotations.

The emergence of social market is no longer a simple tool of life tools, is the embodiment of the designers, consumers in the cultural, taste, emotional and other spiritual needs, the international industrial design for the product design of the national cultural emotional appeal very seriously. The 
needs of these national culture needs of industrial design around the user to carry out the design, attention to human needs while focusing on cultural connotations. From the social development point of view, when the rise of great powers, along with the improvement of national self-confidence, people continue to realize the value of traditional symbols.

The extensive use of traditional symbols in design reflects the confidence of local designers in the national culture and the strong attraction of Chinese traditional culture to foreign designers. Under the globalization and diversified economic forms, the development of cultural industry, Only through the difference in design to win the market, the Chinese elements of mining is actually a strategic choice.

The Connotation of Chinese Traditional Elements. Chinese people advocating harmony, "theory that man is an integral part of nature--Yin and Yang balance" Is the essence of ancient Chinese culture, Confucianism and Taoism are both recognized and adopted the philosophy of Chinese traditional culture is the most far-reaching nature of the source, the spirit embodied in the inclusive and harmonious, and inclusive inevitably derived from diversity. The concept of "harmonious" applied to product design, is to reflect the form, function and coordination of the diversity of modeling, embodied in the human and nature, social integration.

Modern industrial design embodies this harmonious philosophy symbol. Product proportion and scale, symmetry and balance, contrast and unity are in the pursuit of a visual balance and harmony. Color in the product mix is also based on color harmony. On behalf of the contemporary, the local people's aesthetic consciousness, shape in the organic or geometric shape processing, the proportion of lines, are added with a specific meaning. A symbol of specific geographical and cultural characteristics.

China traditionally has a particular preference for a particular form or line, such as the collocation of a square with a circle, because the ancients considered the circle to be square, so the preference side and round with.

\section{Chinese Elements and Its Application in Industrial Design}

People's customs and habits, spiritual civilizations are derived from traditional culture and customs. Various countries and regions have their own different traditional culture Egypt Nile civilization, China's modern design development in its infancy, to be developed a lot of design, the German industrial design simple functional humanity, the Swedish industrial design details, the Danish design Of the focus on comfort and applicability, which we can be signed by the use of Chinese modern design.

The broad and profound culture of the Chinese nation provides rich resources for product design. As one of the ancient civilizations with a long history of culture, China has left rich cultural treasures from the ancient times, the bronze period to the modern industrialization and the high-tech modern civilization production. The long course of development of the Chinese nation for thousands of years has left us a rich cultural treasure. In recent years, people attach importance to the traditional culture, and now many products through the use of Chinese Peking Opera, ceramics, calligraphy, pictures, Chinese zodiac, traditional patterns, the ancient Chinese elements in the design of the people to make people enjoyable works.

\section{How to Apply Chinese Traditional Elements in Industrial Design}

Excellent industrial design must be comprehensive and accurate understanding of the development of traditional elements of the background and significance.

For a good design only to truly understand the meaning and significance of traditional Chinese elements in order to avoid the superficial application of the surface in order to make works to be classic and practical. For example, when you see the Sheraton Hotel in Jiuzhaigou, you will see the Hong Kong-style and modern hotel and the perfect combination of local ethnic style. The hotel is located in the heart of the city. Into just the right, so totally natural. For example, Chanel watches dial collection of Chanel lady's house in China ebony lacquer screen pattern, the use of Geneva's 
traditional techniques to enamel process to create exquisite micro-painted patterns.

In the different historical periods of China have a variety of ideas and culture, in the Spring and Autumn Period, a hundred schools of thought contend, the Tang Dynasty's enlightened prosperity, the Song Dynasty Neo-Confucianism, these cultures are to a large extent affected some of the social culture and crafts And the design of life and production supplies, so when we use certain elements, we should first learn more about the story behind it and some of its moral, so that the correct elements appear in the right place.

So, how to optimize the form of traditional Chinese elements, it is suitable for modern industrial design style. To car design, for example, in the car design, the Chinese elements should be reflected in the doctrine of the mean, harmony. These are not only reflected in the design, but also on the details of the design. Car styling should also learn from, but not simply mechanically applied, but extract the essence of elements --- lines. For the Chinese tradition, the lines not only have the width, thickness, and direction, and even can show the speed and power, the understanding of the lines based entirely on subjective feelings. In the car design, how to design a reasonable expression of the Chinese line width, thickness and even speed and strength, is designed to contain the key elements of Chinese cars. This requires us to look for Chinese lines, from Chinese painting, the traditional daily necessities, handicraft design, as well as architectural design, and all the design to absorb nutrients.

In this regard, Chinese designers must first learn Chinese culture and grasp the essence of Chinese culture. China now has a large number of colleges and universities in the design department, but there is still little emphasis on cultivating Chinese culture. We used a lot of Chinese elements, here are just some of the elements can be used in car design: double happiness, clouds, Chinese section, Kirin, Fu, carp, calligraphy and seal.

Looking for a variety of traditional elements of the prospects of the period, and some even very long, and to combine with modern products, designers require flexibility in the use of grasp the sense of propriety. With the development of modern science and technology, he can put many of the traditional elements of the traditional; some cannot be achieved through the rational combination of material color modeling innovation. To create a classic for.

\section{Summary}

The Chinese nation has a history of 5,000 years. My industrial design is bound to go out of the country with China's economic development. This design will have a history of innovation and modernity, combine the classical art with the development of modern science and technology, and pursue a change. The pursuit of the ideal of the new China dream, creating unprecedented works of the present.

\section{References}

[1] Yin Dingbang, Hong Shao: Introduction to Design (People 's Fine Arts Publishing House, China2013).

[2] Rowling Lipton. Beyond the Cultural Design (China Youth Publishing House, China1998) .

[3] Min Jia, Xia Zhong: Science and technology to get rich guide. Vol. 2(2010), No.24, p. 17.

[4] Hong Meng: Private Science and Technology .Vol. 3(2011), No.2, p. 94.

[5] Yan Chen: Packaging world. Vol. 1(2011), No.1, p. 60.

[6] Hui Li, Kaiying La: China Science and Technology Information. Vol. 1(2007), No.15, p. 83.

[7] Ke Qiu,Minglang Yang,Chaohong Wan: Packaging Engineering. Vol. 33(2012), No.10, p. 50.

[8] Nan Zhang: Mechanical Engineering and Automation. Vol. 6(2015), No.6, p. 222.

[9] Dan Xiong: Industrial Engineering and Technology. Vol. 1(2013), No.7, p. 47. 
[10] Nan Zhang: China Foreign Investment. Vol. 104(2013), No.4, p.152. 